\title{
Comparative treatment costs for patients with acute myocardial infarction between Finland and Norway
}

\author{
TOR IVERSEN ${ }^{1, *}$ \\ UNTO HÄKKINEN ${ }^{2}$ \\ ${ }^{1}$ Department of Health Management and Health Economics, University of Oslo, Norway \\ ${ }^{2}$ CHESS (Centre for Health and Social Economics), National Institute for Health and Welfare, Helsinki, \\ Finland
}

\begin{abstract}
Previous studies on patients with acute myocardial infarction have found that Finland has higher hospital costs per patient than Norway for the first hospital episode (HEP), while Norway has higher costs during the first year after the initial admission. In this paper, we analyze the variation in treatment costs between Finland and Norway in detail by introducing novel explanatory variables. We find that the distance from the patient's home to the hospital increases hospital costs at a declining scale and one-year hospital costs are higher for low-income patients. The higher one-year hospital costs in Norway are accompanied by a comparatively lower mortality rate. While for HEP, the introduction of new explanatory variables does not explain the greater costs in Finland compared with Norway, for one-year costs, the additional variables explain the greater one-year costs in Norway compared to Finland.
\end{abstract}

JEL classification: D24, I1 1

Key words: costs, estimation, international comparison, register, acute myocardial infarction

\section{Introduction}

Acute myocardial infarction (AMI) is a life-threatening condition that occurs when the blood flow to the heart muscle is abruptly cut off. AMI is usually the result of a blockage in one or more coronary arteries. A blockage can develop due to plaque, which can be caused by various reasons. The majority of patients with AMI in Finland and Norway are above 75 years old. With references to the recent medical literature, Hagen et al. (2015) find that over the past 15 years, percutaneous coronary intervention $(\mathrm{PCI})^{1}$ and coronary artery bypass grafting $(\mathrm{CABG})^{2}$ have increasingly replaced medical therapies such as thrombolysis as the preferred treatment for acute AMI because of their clinical effectiveness both for STElevation Myocardial Infarction (STEMI) and non-STEMI. Furthermore, the ratio of AMI patients treated with PCI has increased, while that receiving CABG has decreased over the same period. Giving AMI patients priority for PCI over CABG is based on two arguments: first, PCI procedures are, in most cases, less costly than CABG in the short run; second, the

\footnotetext{
${ }^{1} \mathrm{PCI}$ is a non-surgical procedure used to treat stenotic (narrowed) arteries of the heart.

${ }^{2} \mathrm{CABG}$ is a surgical procedure to restore normal blood flow to an obstructed coronary artery.
}

* Correspondence to: Tor Iversen, Department of Health Management and Health Economics, University of Oslo, Postboks 1089, 0318 Oslo, Norway. E-mail: tor.iversen@medisin.uio.no.

Published: Online January 2019. In print January 2019. dx.doi.org/10.5617/njhe.5543 
relative benefits and detriments of CABG versus PCI are similar. Further, for patients with multivessel diseases, CABG is regarded as superior to PCI in the long run (Hagen et al., 2015).

The EuroHOPE project ${ }^{3}$ (Häkkinen et al., 2015; Iversen et al., 2015) studied the variation in AMI hospital treatment costs between Finland, Hungary, Norway and Sweden. Registry data linked at patient level and pooled across countries were used. Variations in patient composition were adjusted for by considering disease history and comorbidities. The results show considerable variation in treatment costs per patient both within and between countries. The variations also depend on the length of the time period. While Finland has higher hospital costs per patient than Norway for the first hospital episode (HEP), Norway has higher hospital costs than Finland during the first year after the initial admission. Policyrelevant conclusions and implications require more knowledge about the background behind the variations in treatment costs between countries. The recent availability of hospital data covering Finland and Norway over 2009 - 2014 made it possible to further the study of these two countries. In this descriptive study, we thus present more detailed results of the variations between Finland and Norway according to observation period length. Although we shall disaggregate and explain variables related to the differences in treatment costs, this paper is descriptive since our data do not allow for a causal analysis, as interpreted in modern econometrics literature. However, our paper provides novel and detailed knowledge on factors behind relative treatment costs in the two countries. Since both countries share characteristics of the Nordic model of health care (Lyttkens et al., 2016), the results can be used to explore variations in the outcomes within the Nordic model.

We first describe the differences in treatment costs between Finland and Norway when only the gender and age composition of patients are adjusted for, similar to Iversen et al. (2015). Second, we introduce the variables that describe patients' disease characteristics, organization of health care, and socio-economic characteristics and are supposed to affect treatment costs. After having estimated the associations between these variables and treatment costs, we assess whether there is still unexplained differences in treatment costs between the two countries.

Variations in the organization of health care for AMI patients between Finland and Norway are mainly related to more centralized emergency care for patients with AMI in Norway compared with Finland. Centralization implies longer travel distances, which may in turn imply longer hospital stays to prevent post-discharge complications. On the other hand, centralization may imply smaller costs per patient due to the potentially positive returns to scale of the specialized treatment for AMI patients.

Higher socio-economic status in terms of education and income is likely to affect both health status and outcome of treatment. Socio-economic status may also influence treatment costs, although the sign of the impact is not clear. On one hand, socio-economic status may contribute to faster recovery from disease and, hence, to smaller treatment costs. On the other hand, it may contribute to superior treatment that adds to hospital costs. Different from previous studies, we now have access to individual level data on socioeconomic status in terms of income and education for both countries.

The mortality rate for AMI patients is higher in Finland than in Norway (Moger et al. 2018). Again, the implications for hospital treatment cost are not straightforward. On one hand, the health economics literature shows that in general health care costs increase with proximity to death. On the other hand, for the treatment of AMI, frail patients are less likely to go through expensive procedures.

\footnotetext{
${ }^{3}$ European Health Care Outcomes, Performance and Efficiency: Project for cross-country comparison of outcome and costs financed by EU $7^{\text {th }}$ Framework
} 
For the first hospital episode (HEP), we find mortality to be negatively associated with hospital costs and the distance to the hospital positively associated with hospital costs at a declining rate. Since Finnish patients have both shorter distances to the hospital and a higher mortality rate, including explanatory variables in the regression adds to the magnitude of the unexplained differences in hospital costs between the countries. For oneyear hospital costs, the structure of the results is similar. However, the introduction of explanatory variables contributes to explaining the lower treatment costs in Finland.

This study makes three contributions to the literature on cross-country cost analysis. First, the data and analysis include patients treated for a disease from entire countries, not just subgroups. Hence, the potential selection of patients is not an issue and the data are sufficient for country-level comparisons. Second, we develop methods for calculating the resource uses applicable to diverse accounting systems and their registration of resource use across countries. Particularly, we use Finnish micro data to estimate a cost indicator at patient level. Finally, the data include treatment information that extends beyond HEP and accounts for transfers between hospitals. Hence, we can study variations in costs both regarding treatment content and length.

The structure of the paper is as follows. Section 2 explains the study setting and research questions. Section 3 describes the data and provides summary statistics. Section 4 explains the methods. Section 5 presents the results and Section 6 concluding remarks.

\section{Study setting and research questions}

In Finland (population 5.5 million people), municipalities are responsible for financing most health and social services. Most hospitals are owned by hospital districts, which are federations of municipalities. Municipalities finance hospital districts by reimbursement methods decided locally. Although the classification of hospital visits and stays according to Diagnostic Related Groups (DRGs) is used in most hospital districts, it is not centrally decided beforehand and its main aim is not motivating increases in activity and the efficient production of hospital services but equalizing the municipal financing so that it is based on an accurate use of services. Patients pay a small copayment for hospital outpatient visits and inpatient stays.

In Norway (population 5.3 million people), health care is provided by a National Health Service in a mixed centralized-decentralized system. General practitioners (GPs) are mostly private practitioners and hospitals are publicly owned, with salaried physicians. Hospitals are state owned and organized under four regional health authorities (RHA). RHAs are responsible for the hospitals in their region. Hospitals receive as revenue a mix of risk-adjusted capitation based on the population in their catchment areas and DRG-based activity-based financing. There is a patient co-payment for outpatient consultations but not for inpatient stays.

Hagen et al. (2015) and Moger et al. (2018) provide a summary of the variation in the organization of treatment between Finland and Norway. The organization of care for AMI patients varies between the two countries. In both Finland and Norway, PCI-operating centers are located in regional urban centers, whose populations have, on average, higher education and income levels. In Norway, the execution of the procedure is far more centralized than in Finland. Only seven centers in Norway performed PCI in 2009, of which five were (public) university hospitals, one a specialized public hospital and the other is a specialized private clinic. In the Finnish health care system, the decision-making is decentralized to hospital districts, each with their own PCI facilities. Altogether, there are 20 PCI centers in university and other central hospitals. In 2009, only two of the PCI centers, both in university hospitals, had formally acute services available 24/7. By 2014, three 
others (two of them university hospitals) have formally established availability of acute services. The others perform PCI under different arrangements, varying from acute services available 24/7 on voluntary basis as an emergency overtime work to services available only during daytime over weekdays. As such, Norwegian AMI patients face longer travel times to a PCI center than Finnish patients. However, in Norway, if travel time by car exceeds 30 minutes, helicopter transport will be used in emergency cases. Further, due to centralization, Norwegian patients are treated in higher-volume hospitals than Finnish patients. Interestingly, Moger et al. (2018) study how differences in the organization of hospital treatment between Finland and Norway affect mortality rates for AMI patients in the two countries. After adjusting for individual and regional variables, they find the mortality to be 2 - 4\% lower in Norway within most categories of hospital system variables. As such, they are not able to explain the mortality differences from the organizational variables. It is therefore of interest to study to what extent the variation in cost is associated with organizational variables.

Socio-economic status is likely to contribute positively to the health outcome of a treatment. First, better-educated patients are generally in better health than less educated ones because of their more favorable lifestyle and health-related behaviors. Second, bettereducated patients are more likely to comply with medical recommendations following treatment (Cutler and Lleras-Muney, 2010). Several studies of AMI patients, show that low socio-economic status adversely affects both access to cardiac procedures such as PCI, and mortality (Alter et al., 1999; Alter et al., 2013; Hetemaa, 2014). Additionally, studies on Finland and Norway show that socio-economic status is related to the health outcome for the treatment of AMI patients. Recently, Hagen et al. (2015) show that socio-economic variables affect access to PCI in both countries, although the direct effects of income and education on mortality after AMI are significantly larger than the indirect effect via PCI access. In addition to treatment outcome, socio-economic status might also have an impact on AMI treatment costs. Since patients with higher socio-economic status are in general in a better health condition, they may recover faster from an AMI, with potentially smaller hospital costs compared to patients with lower socio-economic status. On the other hand, patients with high socio-economic status and their relatives may be more able to achieve high quality and costly treatment compared with patients with low socio-economic status. Hence, the total effect is difficult to conjecture. Since the distribution of socio-economic status according to education and income differs between Finland and Norway, we adjust for education and income when we compare treatment costs across the two countries.

The research questions are related to the possible reasons for the pattern of cost variations identified in previous studies. We examine research questions on organization of care, outcome of care, patients' socio-economic status and unexplained factors:

1. Organization: Are differences in hospital treatment costs associated with differences in the organization of hospital care?

2. Process and outcome of care: Are differences in hospital treatment costs associated with differences in the process and outcome of care?

3. Socio-economic status: Are differences in hospital treatment costs associated with differences in socio-economic status?

4. Unexplained: Are there still unexplained differences in treatment costs between Finland and Norway when the variables predicted to be associated with treatment costs are adjusted for? 


\section{Data and descriptive statistics}

We use data for the incidence and treatment of AMI over 2009 - 2014 in Finland and Norway. Data are provided by hospital discharge (inpatient stays and outpatient visits), cause-of-death and education and income ${ }^{4}$ registers in each country.

Adjustment for patient heterogeneity is similar to that in the EuroHOPE project (Häkkinen et al., 2015). To ensure patient homogeneity, all patients with hospital admissions due to AMI in the year before the present AMI admission are excluded (Häkkinen et al., 2013, EuroHOPE, 2016) ${ }^{5}$. Under EuroHOPE, comorbidities were assessed using patients' medical records of the previous year from two data sources: i)primary or secondary diagnoses recorded during hospital admissions within 365 days prior to the index admission and ii) purchases of medications that can be linked to particular diagnoses (Moger and Peltola, 2014). Unfortunately, we could not use the second source of comorbidity data due to lack of medication data from Norway. The usual comorbidity measures such as the Charlson/Elixhauser indices are based on information of secondary diagnoses in hospital discharge data for the current admission. The EuroHOPE project did not use this information, because the comorbidity measures based on secondary diagnosis at time of discharge can be partly due to poor care during the index admission. Additionally, there exists considerable variation between the countries in the coding of secondary diagnosis during the index admission and its reporting is deficient in Finland.

In EuroHOPE, the concept of a care episode is crucial. Ideally, the use of resources during an episode of care relates to the entire treatment course from the onset of the disease to the end of the treatment irrespective of the treatment provider types. In practice, a specific date must be defined as the end of the follow-up period. In this paper, the hospital episode begins with the start of the disease (index day) and ends one-year thereafter. The length of HEP is: (discharge day of first hospital episode - index day) +1 . The first hospital episode includes possible transfers between hospitals if an admission starts the same day or the day after the previous admission has ended. We use two measures of cost. The first describes costs during HEP. The second cost measure describes the cost of inpatient care during the one-year follow-up.

In Norway, we followed patients to the end of 2014. Thus, we cannot calculate 365day follow-up for patients treated in 2014. Hence, the study includes patients with index admissions during 2009- 2013.

Table 1 presents descriptive statistics of the sample by country. The patient composition according to age, gender, and occurrence of STEMI is similar between the two countries. A greater proportion of Finnish patients have basic education as the highest level compared with Norwegian patients. The mean income is about $30 \%$ smaller among Finnish patients. Patients from Norway have more hospital days before the index admission and a lower mortality rate during HEP compared with Finnish patients. The mortality difference is maintained according to the one-year perspective. Norwegians have a considerably longer

\footnotetext{
${ }^{4}$ Finland: The Finnish Hospital Discharge Register and Statistics Finland statistics on causes of death, income and education. Norway: Norwegian Patient Register, Causes of Death Registry, and Statistics Norway (education and income). We measure income by the annual gross income of patients. In the Finnish data income is available at the individual level where as in the Norwegian data, income is measured every cohort year by the same 11 income groups defined in Norwegian Kroner (NOK). We compare the absolute incomes as follows. First we divide the Finnish patients into Norwegian income groups using purchasing power parities (PPPs) for 2014. We use the Finnish absolute mean income (€) in each group as measure of income in year 2014. Earlier year income is based on national consumer price indices-adjusted mean income of the income groups. The registry owners are not responsible for our interpretations and analyses of data.
}

${ }^{5}$ For Finland, the excluded patients accounted for 5-6\% of the patients admitted in 2013. Since the excluded patients were deleted from the data file, we cannot provide similar figures for Norway. 
travel time to the admitting hospital, which also treats more patients compared with Finland. This combination of characteristics reveals the more centralized hospital structure in Norway in the treatment of patients with AMI, as explained in Section 2.

Table 1: Descriptive statistics on patient composition and outcome (national comparison 2009 - 2013)

\begin{tabular}{|c|c|c|c|c|c|}
\hline \multirow[b]{2}{*}{ Variable } & \multirow[b]{2}{*}{ Definition } & \multicolumn{2}{|l|}{ FIN } & \multicolumn{2}{|l|}{ NOR } \\
\hline & & Mean & SD & Mean & SD \\
\hline \multicolumn{6}{|c|}{ Binary $(0 / 1)$ variables } \\
\hline a00_39* & 1 if age $<40$ years, 0 otherwise & 0.01 & & 0.01 & \\
\hline a40_49* & 1 if $40 \leq$ age $\leq 49,0$ otherwise & 0.05 & & 0.06 & \\
\hline a50_54* & 1 if $50 \leq$ age $\leq 54,0$ otherwise & 0.05 & & 0.06 & \\
\hline a55_59* & 1 if $55 \leq$ age $\leq 59,0$ otherwise & 0.07 & & 0.08 & \\
\hline a60_64* & 1 if $60 \leq$ age $\leq 64,0$ otherwise & 0.11 & & 0.11 & \\
\hline a65_69* & 1 if $65 \leq$ age $\leq 69,0$ otherwise & 0.11 & & 0.11 & \\
\hline a70_74* & 1 if $70 \leq$ age $\leq 74,0$ otherwise & 0.12 & & 0.11 & \\
\hline a75_79*\$ & 1 if $75 \leq$ age $\leq 79,0$ otherwise & 0.14 & & 0.11 & \\
\hline a80_84* & 1 if $80 \leq$ age $\leq 84,0$ otherwise & 0.16 & & 0.13 & \\
\hline a85_89* & 1 if $85 \leq$ age $\leq 89,0$ otherwise & 0.12 & & 0.13 & \\
\hline a90* & 1 if $90 \leq$ age, 0 otherwise & 0.06 & & 0.09 & \\
\hline Male* & 1 if male, 0 otherwise & 0.61 & & 0.63 & \\
\hline basic_edu $* * \$$ & 1 if basic education, 0 otherwise & 0.60 & & 0.41 & \\
\hline med_edu** & 1 if medium education, 0 otherwise & 0.26 & & 0.44 & \\
\hline upp_edu** & 1 if upper education, 0 otherwise & 0.14 & & 0.15 & \\
\hline STEMI* & 1 if STEMI, 0 otherwise & 0.35 & & 0.34 & \\
\hline Dhep* & 1 if died during HEP, 0 otherwise & 0.11 & & 0.07 & \\
\hline $\mathrm{d} 365^{*}$ & 1 if died over 1 year, 0 otherwise & 0.23 & & 0.18 & \\
\hline d365acs* & 1 if death diagnosis $\mathrm{I} 20-\mathrm{I} 22,0$ otherwise & 0.54 & & 0.40 & \\
\hline \multicolumn{6}{|c|}{ Continuous variables } \\
\hline Mincome** & $\begin{array}{l}\text { income based on mean income of income } \\
\text { groups }\end{array}$ & 20378 & 17134 & 29813 & 22354 \\
\hline Lospy* & \#hospital days previous year & 3.17 & 8.79 & 4.09 & 10.54 \\
\hline $\operatorname{surv} 365^{*}$ & \#days alive over 1 year & 298.45 & 131.43 & 315.43 & 114.73 \\
\hline t_hephosp** & $\begin{array}{l}\text { travel time in minutes to admitting } \\
\text { hospital }\end{array}$ & 35.990 & 44.19 & 95.12 & 130.19 \\
\hline vol_hephosp** & volume of patients & 477.24 & 368.31 & 952.41 & 776.64 \\
\hline \multicolumn{2}{|c|}{ Observations (HEP)* } & \multicolumn{2}{|c|}{41851} & \multicolumn{2}{|l|}{50905} \\
\hline \multicolumn{2}{|c|}{ Observations (HEP) t_hephosp, vol_hephosp edu mincome)** } & \multicolumn{2}{|c|}{41703} & \multicolumn{2}{|l|}{45786} \\
\hline \multicolumn{2}{|c|}{ Observations (one-year) } & \multicolumn{2}{|l|}{40205} & \multicolumn{2}{|l|}{47105} \\
\hline \multicolumn{2}{|c|}{ Observations (one-year) t_hephosp, vol_hephosp edu mincome) } & \multicolumn{2}{|l|}{40057} & \multicolumn{2}{|l|}{42413} \\
\hline
\end{tabular}

$\$$ indicates reference value 


\section{Methods}

We construct indicators for hospital costs during HEP and the first year after the index admission. Because cost figures are not commonly provided at patient level, researchers typically rely on aggregated amounts, occasionally supplemented with information from hospitals that use cost-per-patient (CPP) figures. Alternative methods for cost calculations may result in variations in cost figures, thus considerably influencing cost estimations and comparisons. Geue et al. (2012) illustrate this issue by using data from Scotland to compare five costing methods. Their descriptive statistics show substantial variation in the costs for alternative costing methods. These differences also carry over to the differences in cost estimates from regression analyses. The authors conclude that the costing method substantially influences any inference from econometric cost modeling that assesses the marginal effect of the explanatory variables. The EuroDRG-project highlights this conclusion, finding considerable variation in the explanatory power of DRGs across countries and by treatment types (Busse, 2012). Particularly, this variation may be due to differences in the construction of country-specific DRG systems. Therefore, comparisons of cost figures across institutions and countries are problematic and standardizing costing methods is unlikely in the near future.

In EuroHOPE, three complementary approaches to the construction of cost indicators were used. First, resource use was expressed in terms of weighed procedures and hospital days based on Swedish CPP data. Second, resource use was expressed in terms of national DRG systems with their respective weights. Finally, resource use was expressed in terms of the common Nordic DRG system with Finnish weights. Each approach has its strengths and weaknesses (Iversen et al., 2015). For example, the disadvantage of the second approach is that the cost assignment system is likely to vary across countries. Hence, systematic bias may be introduced into country-level comparison. Moreover, for AMI patients the DRG system does not explain costs well (Häkkinen et al., 2012), which restricts the use of the second and third approaches. In this paper, we extend the first approach by making use of detailed micro cost data from Finnish hospitals.

In Finland, most university hospitals and to some extent other central hospitals have an advanced cost accounting system (Kautainen et al., 2011). In this system, cost accounting starts with the calculation of overhead costs, which are then allocated to lower organizational levels using a top-to-bottom approach. All overhead costs (e.g., administrative costs) are allocated to the organizational levels that produce hospitalization days, outpatient visits, surgery, and ambulatory procedures. After this stage, a bottom-up cost analysis phase starts. For each treated patient, the following costs are defined: nursing (basic care: "price of hospital day"), procedures undertaken in the operation room and ambulatory care, radiology, laboratory tests, expensive drugs, blood products, and pathological services. The bottom-up cost accounting is undertaken in each hospital at department level. The patient-level information on costs is included in the hospital discharge register from those hospitals that have an advanced cost accounting system. We gathered cost data from those patients with credible cost data from HEP admissions $(n=8690)$ and all inpatient hospital care episodes in the one-year follow-up $(n=6695)$. The costs are deflated into 2014 prices using the Finnish price index of municipal health services.

We assume that the intermediate products that explain the costs of the initial AMI hospital stay are main procedures and length of stay. The procedures we include are CABG and PCI. We regress the costs of individual Finnish patients with credible cost data against intermediate products, and predict the costs for all patients from estimated coefficients and the magnitude of the intermediate products. For one-year costs, we also distinguish between hospital days with AMI as main diagnosis and hospital days with other main diagnoses. 
The best way to estimate health care costs has been extensively discussed in the literature (Manning, 2006, 2012; Mullahy, 2009; Mihaylova et al., 2011). For instance, Mullahy (2009) points out four prominent features of health care expenditure: (1) data on costs are, for most practical purposes, nonnegative; (2) a sizable fraction of the observations are 0; (3) data exhibit "heavy" upper tails; and (4) data are right-skewed. In this project, all these features except the second point are important for comparing the treatment costs for patients with a specific diagnosis. We compare four model specifications that are frequently used in cost analysis in health economics (Deb et al., 2017): ordinary least squares regression (OLS), OLS with ln cost, generalized linear model (GLM) with log link, and gamma distribution and GLM with log link and Poisson distribution. We choose the best model based on goodness-of-fit measures that include pseudo $\mathrm{R}^{2}$ (in regression between measured and predicted value) and the root mean square error (RMSE) defined by

$$
R M S E=\sqrt{\sum_{i=1}^{n}\left(y_{i}-\hat{y}_{i}\right)^{2} / n},
$$

where $n$ is the sample size, $y_{i}$ the cost-indicator for individual $i$, and $\hat{y}_{i}$ the predicted cost. We also use the mean absolute prediction error (MAPE) for model selection:

$$
M A P E=\sum_{i=1}^{n} a b s\left(y_{i}-\hat{y}_{i}\right) / n .
$$

Since the predicted cost estimator is based on Finnish hospitals, it is implicitly assumed that the relative costs of intermediate products in other hospitals are equal to the relative costs of Finnish hospitals with patient-level cost accounting. The calculated cost indicators are an aggregate of the intermediate products with weights from Finnish hospitals.

In stage two, we estimate the associations between predicted costs and variables at the level of patients (age, gender, previous hospital use, type of AMI and socio-economic variables) and hospitals (travel distance and volume) and the fixed unexplained variation between countries. Again, we run OLS, OLS with ln cost, GLM with log link and gamma distribution and GLM with log link and Poisson distribution, and perform specification tests as explained above. All regressions are run with year fixed effects. Since the cost indicator is a predicted value from previous regressions with Finnish micro cost data, we calculate standard errors by bootstrapping with 100 replications.

\section{Results}

Model choice is based on the goodness-of-fit evaluated by RMSE, MAPE and $\mathrm{R}^{2}$, as described in Section 4. OLS yields smaller RMSE and MAPE and higher $\mathrm{R}^{2}$ (see Table 2 for details) for cost regressions during both periods and the cost comparison during HEP. For the one-year cost comparison, the logarithmic model and GLM (log-Poisson) have the best scores. We then use OLS for cost comparison according to HEP and GLM (logPoisson) for the one-year cost comparison.

Table 3 shows the results for cost regression for HEP and one-year hospital costs. Both surgical procedures and hospital days influence costs. The marginal effect of one hospital day is about EUR 830 irrespective of whether we consider HEP or one-year costs.

Table 4 shows the descriptive statistics according to the treatment composition and predicted costs based on the estimated coefficients in Table 3. Since Table 3 only includes Finnish hospitals that provide cost data at patient level and Table 4 includes all hospitals, Table 4 has more observations than Table 3. The descriptive pattern of Iversen et al. (2015) is replicated here: predicted costs during HEP are highest in Finland while one-year ones are highest in Norway. Since the occurrence rates of surgical procedures during HEP are approximately equal in the two countries, the differences in predicted HEP costs are due to the longer hospital stays during HEP in Finland than in Norway. Additionally, in the one- 
Table 2: Goodness of fit tests

\begin{tabular}{|c|c|c|c|c|}
\hline & $\begin{array}{l}\text { OLS } \\
\text { on y }\end{array}$ & $\begin{array}{l}\text { OLS } \\
\text { on } \ln (y)\end{array}$ & $\begin{array}{l}\text { GLM } \\
(\log - \\
\text { gamma) }\end{array}$ & $\begin{array}{l}\text { GLM } \\
\text { (log- } \\
\text { Poisson) } \\
\end{array}$ \\
\hline \multicolumn{5}{|l|}{ RMSE } \\
\hline HEP cost regression from Finnish micro data (Table 3 ) & 3209 & 4523 & 4407 & 3424 \\
\hline One-year cost regression from Finnish micro data (Table 3) & 5297 & 40313 & 80990 & 8604 \\
\hline HEP cost comparison (Table 5) & 7075 & 7594 & 7271 & 7270 \\
\hline One-year cost comparison (Table 6) & 10505 & 10612 & 10307 & 10284 \\
\hline Cost comparison patients alive (Table 6) & 13673 & 14949 & 20976 & 14207 \\
\hline Cost comparison patients deceased (Table 6) & 13531 & 14612 & 14229 & 13685 \\
\hline \multicolumn{5}{|l|}{ MAPE } \\
\hline HEP cost regression from Finnish micro data (Table 3) & 1921 & 2147 & 2153 & 2006 \\
\hline One-year cost regression from Finnish micro data (Table 3) & 2720 & 4615 & 6134 & 3363 \\
\hline HEP cost comparison (Table 5) & 4118 & 4018 & 4301 & 4295 \\
\hline One-year cost comparison (Table 6) & 6288 & 5809 & 6163 & 6153 \\
\hline Cost comparison patients alive (Table 6 ) & 9856 & 8847 & 10025 & 9920 \\
\hline Cost comparison patients deceased (Table 6) & 9401 & 9267 & 9811 & 9544 \\
\hline \multicolumn{5}{|l|}{ Pseudo $\mathbf{R}^{2}$} \\
\hline HEP cost regression from Finnish micro data (Table 3) & 0.57 & 0.45 & 0.48 & 0.52 \\
\hline One-year cost regression from Finnish micro data (Table 3) & 0.73 & 0.16 & 0.11 & 0.45 \\
\hline HEP cost comparison (Table 5 ) & 0.10 & 0.03 & 0.05 & 0.05 \\
\hline One-year cost comparison (Table 6) & 0.36 & 0.39 & 0.39 & 0.39 \\
\hline Cost comparison patients alive (Table 6 ) & 0.06 & 0.01 & 0.01 & 0.02 \\
\hline Cost comparison patients deceased (Table 6) & 0.27 & 0.22 & 0.23 & 0.25 \\
\hline
\end{tabular}

year perspective, the proportion of patients having surgical procedures is similar in the two countries, while the total length of stay is longer in Norway. The longer length of stay in Norway is due to hospital admissions with a main diagnosis other than AMI. Therefore, the additional length of stay in Norway may well be unrelated to the initial AMI episode. Overall, length of stay for AMI admissions is still longer in Finland than Norway.

We now proceed with the regression-based comparison of HEP costs. Since OLS shows smaller RMSE and MAPE and greater $\mathrm{R}^{2}$ in the within sample validation, we continue with OLS (see Table 2 for details). Table 5 shows the results of the comparison of predicted costs between the two countries when socio-demographic adjustments at patient level are first included, then disease characteristics, then hospital and residential characteristics, and finally socio-economic variables in terms of education and income. All regressions are performed with fixed effects for years and standard errors are clustered at hospital level. Since estimation is done by OLS, the estimated coefficients have their magnitudes expressed in euros. In specification (1), the country dummy is not statistically significantly different from zero, when there is only a country fixed effect in addition to fixed effects for years. When we adjust for socio-demographic variables in addition to STEMI and number of hospital days during the previous year, there is still no significant country effect. Of the adjustment variables, the presence of STEMI increases cost by about $7 \%$. When mortality variables are included, death during HEP reduces the predicted costs by more than EUR 2200, which is a third of hospital costs. In specification (5), we also include hospital variables in terms of distance and volume and, finally, specification (6) 
Table 3: Cost regression from Finnish micro data

\begin{tabular}{llll}
\hline Variable & Definition & $\begin{array}{l}\text { Predhepcost } \\
\text { EURO }\end{array}$ & $\begin{array}{l}\text { pred365cost } \\
\text { EURO }\end{array}$ \\
\hline hepcabg & 1 if CABG during HEP, 0 otherwise & $\begin{array}{l}6682.3^{* * *} \\
(602.6)\end{array}$ & \\
heppci & 1 if PCI during HEP, 0 otherwise & $\begin{array}{l}3653.2^{* * *} \\
(603.4)\end{array}$ & \\
heplosc & LOS (length of stay) during HEP & $833.7^{* * *}$ & \\
& & $(49.2)$ & \\
cabg365 & 1 if CABG over 1 year, 0 otherwise & & $8402.0^{* * *}$ \\
& & & $(479.0)$ \\
pci365 & Number of PCI during 1 year & & $2918.7^{* *}$ \\
& & & $(728.1)$ \\
los365ac & AMI LOS over 1 year & & $830.4^{* * *}$ \\
& & & $(66.6)$ \\
los365cm & Other LOS over 1 year & $824.8^{* * *}$ \\
& & & $(23.4)$ \\
Constant & & $-1172.3^{*}$ & -1340.2 \\
& & $(402.8)$ & $(418.1)$ \\
\hline $\mathrm{N}$ & & 8690 & 6695 \\
Fixed effect years & & & $\sqrt{ }$ \\
$\mathrm{r}^{2}$ & & 0.570 & 0.737 \\
\hline
\end{tabular}

Standard errors in parentheses. ${ }^{*} \mathrm{p}<0.05,{ }^{* *} \mathrm{p}<0.01,{ }^{* * *} \mathrm{p}<0.001$

adds patient education and income. Distance contributes to higher costs at a declining rate, while hospital volume, patient income and education show no significant association with costs. The lack of impact for socio-economic variables also applies when either education or income is included. The country effect increases as more adjustment variables are included because Finland has a higher mortality rate and shorter distance from a patient's residential municipality to the hospital. Since both these variables lead to lower predicted costs, the country fixed effect has a greater magnitude and statistically significantly positive estimate for Finland.

Since GLM with log link and Poisson distribution has smaller RMSE and MAPE and greater $\mathrm{R}^{2}$ in the within-sample validation of one-year costs, we continue the analyses with GLM with log link and Poisson distribution. Table 6 shows the regression results with fixed effects for years and standard errors clustered at hospital level. When only the country dummy is included, the predicted one-year cost in Finland is EUR 1065 lower than in Norway. When adjusters are included, the estimated coefficient of the country dummy becomes smaller in magnitude and also fails to be statistically significant. A patient who dies during the first year must live more than 241 days to exceed the treatment costs of a patient who survives the entire year. As before, the distance to hospital contributes positively to costs. Since the characteristics that contribute to smaller costs are more prevalent among Finnish patients, the introduction of these variables implies country fixed effect is no longer statistically significant. From specification (6), higher income is associated with smaller one-year costs. 


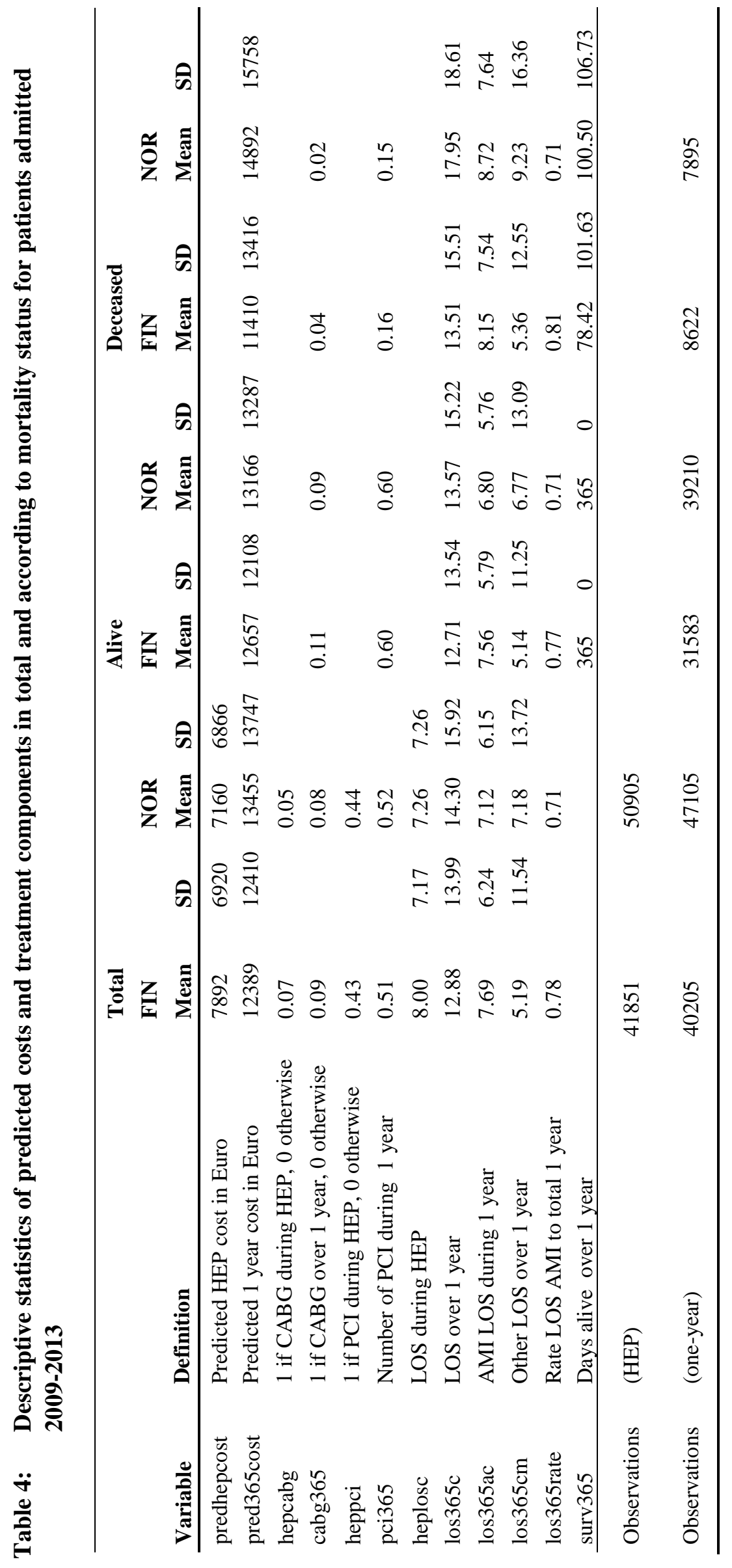


Table 5: HEP cost comparison in Euro by OLS (patients admitted 2009 - 2013) with year fixed effects. Bootstrapped standard errors with 100 replications.

\begin{tabular}{|c|c|c|c|c|c|c|}
\hline & (1) & (2) & (3) & (4) & (5) & (6) \\
\hline Finland & $\begin{array}{l}732.0 \\
(486.1)\end{array}$ & $\begin{array}{l}608.6 \\
(455.7)\end{array}$ & $\begin{array}{l}618.9 \\
(370.1)\end{array}$ & $\begin{array}{l}714.8 \\
(401.2)\end{array}$ & $\begin{array}{l}1412.0^{* *} \\
(434.8)\end{array}$ & $\begin{array}{l}1402.6^{* *} \\
(455.5)\end{array}$ \\
\hline a00_39 & & $\begin{array}{l}-2457.7^{* * * *} \\
(269.1)\end{array}$ & $\begin{array}{l}-2468.9^{* * * *} \\
(263.1)\end{array}$ & $\begin{array}{l}-2621.0^{* * * *} \\
(270.6)\end{array}$ & $\begin{array}{l}-2750.1^{* * * *} \\
(264.4)\end{array}$ & $\begin{array}{l}-2741.8^{* * * *} \\
(274.8)\end{array}$ \\
\hline a40_49 & & $\begin{array}{l}-1845.1^{* * *} \\
(215.1)\end{array}$ & $\begin{array}{l}-1859.9^{* * *} \\
(193.6)\end{array}$ & $\begin{array}{l}-2035.9^{* * *} \\
(214.8)\end{array}$ & $\begin{array}{l}-2211.7^{* * *} \\
(191.3)\end{array}$ & $\begin{array}{l}-2191.9^{* * * *} \\
(228.4)\end{array}$ \\
\hline a50_54 & & $\begin{array}{l}-1376.4^{* * *} \\
(214.5)\end{array}$ & $\begin{array}{l}-1392.3^{* * *} \\
(206.4)\end{array}$ & $\begin{array}{l}-1560.1^{* * * *} \\
(178.3)\end{array}$ & $\begin{array}{l}-1708.6^{* * * *} \\
(163.6)\end{array}$ & $\begin{array}{l}-1688.4^{* * * *} \\
(205.0)\end{array}$ \\
\hline a55_59 & & $\begin{array}{l}-1046.0^{* * * *} \\
(162.9)\end{array}$ & $\begin{array}{l}-1054.4^{* * * *} \\
(170.7)\end{array}$ & $\begin{array}{l}-1214.7^{* * * *} \\
(158.6)\end{array}$ & $\begin{array}{l}-1402.6^{* * * *} \\
(171.3)\end{array}$ & $\begin{array}{l}-1384.0^{* * * *} \\
(190.7)\end{array}$ \\
\hline a60_64 & & $\begin{array}{l}-684.6^{* * *} \\
(194.7)\end{array}$ & $\begin{array}{l}-693.4^{* * * *} \\
(189.6)\end{array}$ & $\begin{array}{l}-836.1^{* * *} \\
(190.8)\end{array}$ & $\begin{array}{l}-977.8^{* * *} \\
(179.7)\end{array}$ & $\begin{array}{l}-965.8^{* * *} \\
(184.6)\end{array}$ \\
\hline a65_69 & & $\begin{array}{l}-150.0 \\
(130.3)\end{array}$ & $\begin{array}{l}-154.0 \\
(130.0)\end{array}$ & $\begin{array}{l}-256.6^{*} \\
(120.0)\end{array}$ & $\begin{array}{l}-387.8^{* * *} \\
(100.5)\end{array}$ & $\begin{array}{l}-380.7^{* *} \\
(123.0)\end{array}$ \\
\hline a70_74 & & $\begin{array}{l}9.917 \\
(120.0)\end{array}$ & $\begin{array}{l}5.495 \\
(108.0)\end{array}$ & $\begin{array}{l}-51.78 \\
(109.2)\end{array}$ & $\begin{array}{l}-120.5 \\
(98.38)\end{array}$ & $\begin{array}{l}-119.5 \\
(129.5)\end{array}$ \\
\hline a80_84 & & $\begin{array}{l}-1310.2^{* * *} \\
(134.5)\end{array}$ & $\begin{array}{l}-1310.3^{* * *} \\
(148.1)\end{array}$ & $\begin{array}{l}-1213.2^{* * *} \\
(132.9)\end{array}$ & $\begin{array}{l}-1071.2^{* * * *} \\
(122.1)\end{array}$ & $\begin{array}{l}-1071.7^{* * * *} \\
(126.7)\end{array}$ \\
\hline a85_89 & & $\begin{array}{l}-2538.1^{* * * *} \\
(187.1)\end{array}$ & $\begin{array}{l}-2524.4^{* * * *} \\
(167.0)\end{array}$ & $\begin{array}{l}-2347.3^{* * *} \\
(175.5)\end{array}$ & $\begin{array}{l}-2044.8^{* * * *} \\
(153.2)\end{array}$ & $\begin{array}{l}-2045.2^{* * * *} \\
(156.1)\end{array}$ \\
\hline a90 & & $\begin{array}{l}-3617.2^{* * * *} \\
(271.0)\end{array}$ & $\begin{array}{l}-3593.4^{* * * *} \\
(218.4)\end{array}$ & $\begin{array}{l}-3288.3^{* * * *} \\
(226.4)\end{array}$ & $\begin{array}{l}-2880.2^{* * * *} \\
(207.2)\end{array}$ & $\begin{array}{l}-2881.5^{* * * *} \\
(228.3)\end{array}$ \\
\hline Male & & $\begin{array}{l}628.2^{* * *} \\
(67.32)\end{array}$ & $\begin{array}{l}616.2^{* * *} \\
(59.06)\end{array}$ & $\begin{array}{l}635.6^{* * *} \\
(68.90)\end{array}$ & $\begin{array}{l}594.1^{\text {**** }} \\
(60.80)\end{array}$ & $\begin{array}{l}610.0^{* * * *} \\
(69.02)\end{array}$ \\
\hline STEMI & & & $\begin{array}{l}434.9^{* * *} \\
(81.84)\end{array}$ & $\begin{array}{l}518.1^{\text {**** }} \\
(102.8)\end{array}$ & $\begin{array}{l}484.3^{* * * *} \\
(93.10)\end{array}$ & $\begin{array}{l}483.9^{* * *} \\
(111.0)\end{array}$ \\
\hline Lospy & & & $\begin{array}{l}16.26^{* * * *} \\
(3.488)\end{array}$ & $\begin{array}{l}21.02^{* * *} \\
(3.003)\end{array}$ & $\begin{array}{l}25.88^{* * * *} \\
(4.164)\end{array}$ & $\begin{array}{l}25.74^{* * *} \\
(3.684)\end{array}$ \\
\hline Dhep & & & & $\begin{array}{l}-2287.1^{* * *} \\
(173.0)\end{array}$ & $\begin{array}{l}-2243.4^{* * * *} \\
(161.5)\end{array}$ & $\begin{array}{l}-2244.2^{* * *} \\
(162.0)\end{array}$ \\
\hline t_hephosp & & & & & $\begin{array}{l}9.7^{* * *} \\
(1.6)\end{array}$ & $\begin{array}{l}9.7^{* * * *} \\
(1.6)\end{array}$ \\
\hline sq_t_hephosp & & & & & $\begin{array}{l}-0.01^{\text {** }} \\
(0.00)\end{array}$ & $\begin{array}{l}-0.01^{* * *} \\
(0.00)\end{array}$ \\
\hline vol_hephosp & & & & & $\begin{array}{l}0.6 \\
(0.6)\end{array}$ & $\begin{array}{l}0.6 \\
(0.6)\end{array}$ \\
\hline Mincome $(€ 10000)$ & & & & & & $\begin{array}{l}-21.7 \\
(14.5)\end{array}$ \\
\hline med_edu & & & & & & $\begin{array}{l}51.4 \\
(53.2)\end{array}$ \\
\hline upp_edu & & & & & & $\begin{array}{l}-6.3 \\
(83.8)\end{array}$ \\
\hline Constant & $\begin{array}{l}7070.8^{* * *} \\
(382.3)\end{array}$ & $\begin{array}{l}7894.7^{* * *} \\
(339.3)\end{array}$ & $\begin{array}{l}7646.1^{* * * *} \\
(336.1)\end{array}$ & $\begin{array}{l}7755.9^{* * *} \\
(312.2)\end{array}$ & $\begin{array}{l}6549.5^{* * *} \\
(471.1)\end{array}$ & $\begin{array}{l}6570.6^{* * *} \\
(470.2)\end{array}$ \\
\hline $\mathrm{r} 2$ & 0.00385 & 0.0341 & 0.0354 & 0.0435 & 0.0542 & 0.0542 \\
\hline $\mathrm{N}$ & 92756 & 92756 & 92756 & 92756 & 87489 & 87489 \\
\hline
\end{tabular}


Table 6: One-year cost comparison in euro by GLM log Poisson total and according to mortality status (by OLS) with year fixed effects (patients admitted 2009 - 2013). Bootstrapped standard errors with 100 replications.

\begin{tabular}{|c|c|c|c|c|c|c|c|c|}
\hline \multirow{2}{*}{ Finland } & (1) & (2) & (3) & (4) & (5) & (6) & Alive & Deceased \\
\hline & $\begin{array}{l}-1064.6^{*} \\
(496.5)\end{array}$ & $\begin{array}{l}-1302.9^{* *} \\
(451.7)\end{array}$ & $\begin{array}{l}-1114.8^{*} \\
(483.3)\end{array}$ & $\begin{array}{l}-841.2 \\
(441.6)\end{array}$ & $\begin{array}{l}-541.8 \\
(606.2)\end{array}$ & $\begin{array}{l}-698.4 \\
(565.8)\end{array}$ & $\begin{array}{l}-83.28 \\
(633.2)\end{array}$ & $\begin{array}{l}-1741.5^{* *} \\
(583.7)\end{array}$ \\
\hline a00_39 & & $\begin{array}{l}-5437.5^{* * * *} \\
(627.2)\end{array}$ & $\begin{array}{l}-4843.0^{* * * *} \\
(682.7)\end{array}$ & $\begin{array}{l}-4875.8^{* * *} \\
(644.8)\end{array}$ & $\begin{array}{l}-4741.9^{* * * *} \\
(805.0)\end{array}$ & $\begin{array}{l}-4589.0^{* * * *} \\
(820.1)\end{array}$ & $\begin{array}{l}-4389.7^{* * * *} \\
(642.5)\end{array}$ & $\begin{array}{l}100.1 \\
(2388.5)\end{array}$ \\
\hline a40_49 & & $\begin{array}{l}-4933.0^{* * *} \\
(410.1)\end{array}$ & $\begin{array}{l}-4372.9^{* * *} \\
(394.7)\end{array}$ & $\begin{array}{l}-4448.6^{* * *} \\
(415.0)\end{array}$ & $\begin{array}{l}-4520.2^{* * *} \\
(498.8)\end{array}$ & $\begin{array}{l}-4293.8^{* * *} \\
(431.0)\end{array}$ & $\begin{array}{l}-4192.1^{* * *} \\
(367.4)\end{array}$ & $\begin{array}{l}2695.7 \\
(2047.0)\end{array}$ \\
\hline a50_54 & & $\begin{array}{l}-4197.2^{* * * *} \\
(290.1)\end{array}$ & $\begin{array}{l}-3679.6^{* * *} \\
(257.8)\end{array}$ & $\begin{array}{l}-3742.5^{* * *} \\
(294.8)\end{array}$ & $\begin{array}{l}-3704.8^{* * *} \\
(304.2)\end{array}$ & $\begin{array}{l}-3471.5^{* * *} \\
(253.7)\end{array}$ & $\begin{array}{l}-3503.5^{* * *} \\
(226.4)\end{array}$ & $\begin{array}{l}400.5 \\
(1465.0)\end{array}$ \\
\hline a55_59 & & $\begin{array}{l}-3585.0^{* * * *} \\
(294.7)\end{array}$ & $\begin{array}{l}-3088.1^{* * *} \\
(254.1)\end{array}$ & $\begin{array}{l}-3181.1^{* * *} \\
(283.0)\end{array}$ & $\begin{array}{l}-3276.8^{* * * *} \\
(322.7)\end{array}$ & $\begin{array}{l}-3045.9^{* * * *} \\
(309.7)\end{array}$ & $\begin{array}{l}-3205.8^{* * * *} \\
(247.7)\end{array}$ & $\begin{array}{l}893.7 \\
(1238.3)\end{array}$ \\
\hline a60_64 & & $\begin{array}{l}-2539.9^{* * * *} \\
(302.7)\end{array}$ & $\begin{array}{l}-2213.4^{* * *} \\
(308.0)\end{array}$ & $\begin{array}{l}-2289.0^{* * *} \\
(229.1)\end{array}$ & $\begin{array}{l}-2278.5^{* * *} \\
(270.9)\end{array}$ & $\begin{array}{l}-2111.2^{* * * *} \\
(271.0)\end{array}$ & $\begin{array}{l}-2523.7^{* * *} \\
(182.4)\end{array}$ & $\begin{array}{l}2804.0^{* * *} \\
(990.3)\end{array}$ \\
\hline a65_69 & & $\begin{array}{l}-1059.5^{* * *} \\
(265.2)\end{array}$ & $\begin{array}{l}-834.1^{* *} \\
(270.0)\end{array}$ & $\begin{array}{l}-881.2^{* * * *} \\
(198.0)\end{array}$ & $\begin{array}{l}-848.7^{* * *} \\
(247.9)\end{array}$ & $\begin{array}{l}-744.7^{* *} \\
(238.6)\end{array}$ & $\begin{array}{l}-1184.7^{* * * *} \\
(216.0)\end{array}$ & $\begin{array}{l}3038.5^{* * *} \\
(608.8)\end{array}$ \\
\hline a70_74 & & $\begin{array}{l}-445.7^{* *} \\
(166.9)\end{array}$ & $\begin{array}{l}-352.2^{*} \\
(163.5)\end{array}$ & $\begin{array}{l}-391.4^{*} \\
(155.1)\end{array}$ & $\begin{array}{l}-366.5^{*} \\
(162.9)\end{array}$ & $\begin{array}{l}-334.9^{*} \\
(169.5)\end{array}$ & $\begin{array}{l}-505.8^{* *} \\
(183.8)\end{array}$ & $\begin{array}{l}939.1 \\
(538.9)\end{array}$ \\
\hline a80_84 & & $\begin{array}{l}-1052.7^{* * * *} \\
(241.7)\end{array}$ & $\begin{array}{l}-1100.8^{* * *} \\
(221.4)\end{array}$ & $\begin{array}{l}-1045.9^{* * * *} \\
(174.9)\end{array}$ & $\begin{array}{l}-1044.1^{* * * *} \\
(224.8)\end{array}$ & $\begin{array}{l}-1065.5^{* * * *} \\
(216.0)\end{array}$ & $\begin{array}{l}-963.2^{* * *} \\
(270.2)\end{array}$ & $\begin{array}{l}-1585.5^{* * *} \\
(385.9)\end{array}$ \\
\hline a85_89 & & $\begin{array}{l}-2842.1^{* * * *} \\
(257.9)\end{array}$ & $\begin{array}{l}-2846.9^{* * * *} \\
(254.5)\end{array}$ & $\begin{array}{l}-2673.7^{* * * *} \\
(187.4)\end{array}$ & $\begin{array}{l}-2585.6^{* * * *} \\
(246.6)\end{array}$ & $\begin{array}{l}-2610.6^{* * * *} \\
(238.3)\end{array}$ & $\begin{array}{l}-2339.0^{* * * *} \\
(266.4)\end{array}$ & $\begin{array}{l}-3286.2^{* * *} \\
(462.6)\end{array}$ \\
\hline a90 & & $\begin{array}{l}-5086.2^{* * *} \\
(324.2)\end{array}$ & $\begin{array}{l}-5134.0^{* * * *} \\
(386.0)\end{array}$ & $\begin{array}{l}-4755.3^{* * *} \\
(295.8)\end{array}$ & $\begin{array}{l}-4719.0^{* * *} \\
(356.8)\end{array}$ & $\begin{array}{l}-4748.3^{* * * *} \\
(346.1)\end{array}$ & $\begin{array}{l}-3613.2^{* * * *} \\
(379.1)\end{array}$ & $\begin{array}{l}-5203.7^{* * *} \\
(486.6)\end{array}$ \\
\hline Male & & $\begin{array}{l}633.1^{* * * *} \\
(110.5)\end{array}$ & $\begin{array}{l}675.6^{* * * *} \\
(106.0)\end{array}$ & $\begin{array}{l}672.9^{* * * *} \\
(106.1)\end{array}$ & $\begin{array}{l}652.6^{* * * *} \\
(129.1)\end{array}$ & $\begin{array}{l}794.0^{* * * *} \\
(115.5)\end{array}$ & $\begin{array}{l}791.9^{* * * *} \\
(128.7)\end{array}$ & $\begin{array}{l}462.1^{* *} \\
(166.2)\end{array}$ \\
\hline STEMI & & & $\begin{array}{l}-404.5^{* *} \\
(155.3)\end{array}$ & $\begin{array}{l}-242.0 \\
(149.7)\end{array}$ & $\begin{array}{l}-259.4 \\
(174.6)\end{array}$ & $\begin{array}{l}-258.3 \\
(141.0)\end{array}$ & $\begin{array}{l}-249.7 \\
(169.5)\end{array}$ & $\begin{array}{l}-67.40 \\
(267.0)\end{array}$ \\
\hline Lospy & & & $\begin{array}{l}145.1^{* * *} \\
(9.486)\end{array}$ & $\begin{array}{l}149.1^{* * *} \\
(7.936)\end{array}$ & $\begin{array}{l}150.1^{* * *} \\
(7.969)\end{array}$ & $\begin{array}{l}149.4^{* * *} \\
(7.178)\end{array}$ & $\begin{array}{l}338.4^{* * *} \\
(16.92)\end{array}$ & $\begin{array}{l}97.6^{* * *} \\
(10.9)\end{array}$ \\
\hline d365 & & & & $\begin{array}{l}12663.7^{* * *} \\
(396.1)\end{array}$ & $\begin{array}{l}12646.0^{* * *} \\
(519.6)\end{array}$ & $\begin{array}{l}12605.7^{* * *} \\
(474.4)\end{array}$ & & \\
\hline surv365 & & & & $\begin{array}{l}52.5^{* * *} \\
(1.3)\end{array}$ & $\begin{array}{l}52.6^{* * *} \\
(1.7)\end{array}$ & $\begin{array}{l}52.5^{* * *} \\
(1.7)\end{array}$ & & $\begin{array}{l}62.5^{* * *} \\
(1.9)\end{array}$ \\
\hline \multicolumn{2}{|c|}{ t_hephosp } & & & & $\begin{array}{l}5.3^{* *} \\
(2.0)\end{array}$ & $\begin{array}{l}5.0^{*} \\
(2.2)\end{array}$ & $\begin{array}{l}5.8^{* *} \\
(2.3)\end{array}$ & $\begin{array}{l}8.8^{*} \\
(4.5)\end{array}$ \\
\hline \multicolumn{2}{|c|}{ sq_t_hephosp } & & & & $\begin{array}{l}-0.003 \\
(0.002)\end{array}$ & $\begin{array}{l}-0.003 \\
(0.002\end{array}$ & $\begin{array}{l}-0.004^{*} \\
(0.002)\end{array}$ & $\begin{array}{l}-0.002 \\
(0.002)\end{array}$ \\
\hline \multicolumn{2}{|c|}{ vol_hephosp } & & & & $\begin{array}{l}-0.1 \\
(0.7)\end{array}$ & $\begin{array}{l}-0.0 \\
(0.6)\end{array}$ & $\begin{array}{l}-0.0 \\
(0.6)\end{array}$ & $\begin{array}{l}1.5^{*} \\
(0.6)\end{array}$ \\
\hline \multicolumn{2}{|c|}{ Mincome $(€ 10000)$} & & & & & $\begin{array}{l}-163.9^{* * *} \\
(25.4)\end{array}$ & & \\
\hline \multicolumn{2}{|l|}{ med_edu } & & & & & $\begin{array}{l}-103.6 \\
(78.9)\end{array}$ & & \\
\hline upp_edu & & & & & & $\begin{array}{l}-222.4 \\
(118.7) \\
\end{array}$ & & \\
\hline $\mathrm{N}$ & 87310 & 87310 & 87310 & 87310 & 82470 & 82470 & 66779 & 15691 \\
\hline
\end{tabular}


In terms of costs according to mortality status difference between countries, the last two columns of Table 4 show descriptive statistics on whether a patient is alive at the end of the first year after the index admission. The predicted one-year cost for those alive is similar in the two countries. For the deceased, the predicted one-year cost is $30 \%$ higher in Norway compared to Finland. The difference is explained by the difference between countries in one-year hospital length of stay, particularly for stays with diagnoses other than AMI. From Table 4 the longer hospital stay in Norway is positively correlated with a considerably longer time to death.

The last two columns of Table 6 split the sample according to whether a patient is alive at the end of the first year after the index admission. Even when other variables are adjusted for, Finland is estimated to have almost EUR 1750 lower costs for the deceased while there is no difference for those alive.

We have sequentially added covariates in the regressions. After having adjusted for age and gender composition, we first included disease characteristics, then hospital and residential characteristics and finally, socio-economic variables for education and income. Gelbach (2016) shows that the method of sequentially adding covariates may be problematic, since the covariates themselves are internally correlated and, therefore, the order in which they are included matters. To check for potential bias, we alternatively run the regressions with entering hospital and residential characteristics before disease characteristics. Neither the sign nor statistical significance of the variables were affected. The absolute values of some estimated coefficients were negligibly affected.

\section{Concluding remarks}

In this paper, we employ administrative register data to study the differences in treatment costs between Finland and Norway for AMI patients. We first describe the difference in treatment costs between Finland and Norway when only the gender and age composition of patients are adjusted for, similar to Iversen et al. (2015). Then, we introduce variables that describe patients' disease characteristics, organization of health care, and socio-economic variables that are assumed to affect treatment costs. After having estimated the associations between these explanatory variables and treatment costs, we conclude by assessing whether there are still unexplained differences in treatment costs between the countries. We are particularly interested in how variables related to the organization of acute care may influence treatment costs. We find no volume effect, while the distance from home to hospital increases hospital costs at a declining scale. Both geography and organization of care involve longer distances in Norway than in Finland and contribute to higher hospital treatment costs in Norway than Finland. However, the magnitude of cost differences between the two countries is also driven by factors other than the organization of acute hospital care ${ }^{6}$. An important factor is the higher mortality rate among AMI patients in Finland than in Norway that contributes to explaining the lower treatment costs in Finland in the one-year perspective. For HEP, a considerable part of the higher costs in Finland is not explained by the variables we introduce.

A lesson for policy-makers from this study is that the distance to the hospital and organization of acute care matters for costs, but cannot account for total cost differences between the countries. The treatment outcome in terms of mortality seems to matter a lot and more attention should be paid to revealing the mechanisms behind the relationship between hospital costs and mortality.

\footnotetext{
${ }^{6}$ Interestingly, this conclusion corresponds to the conclusion in Moger et al. (2018) who compare mortality rates between the two countries.
} 
In a separate analysis of the Helsinki area and Oslo (Appendix), we study whether including primary care and long-term care (LTC) impacts on the comparison of treatment costs for AMI patients. We find that patients in the Helsinki area have higher total costs than those in Oslo during the one-year follow-up as well. The difference in the structure of oneyear costs may indicate more developed primary care and home help services in Norway compared to Finland. The main reason for the somewhat different capital area figures is patient selection (Häkkinen et al., 2018). In the data set, the number of AMI patients is much smaller in the Helsinki area than in Oslo. In the Helsinki area, the sample includes only patients treated in the Helsinki University Hospital. However, AMI patients are also treated at health centers but these are excluded from the data set since these units also treat LTC patients and the index day (beginning of disease episode) cannot be reliably defined for them. The mean age of patients in the data set is about 66 years in the Helsinki area and 72 years in Oslo, which explains the lower mortality in the Helsinki area compared to Oslo.

Predicted hospital costs rely on micro data from a selection of Finnish hospitals and the hypothesis that variation in costs at patient level can be explained by major procedures and length of stay when standard errors are clustered at hospital level. Table 3 shows that the model explains from $57 \%$ (HEP) to $74 \%$ (one-year) of the variation in costs. This is a better explanatory power than of many DRG-based cost indicators (Busse, 2012). It also means the associations between predicted costs and the right hand side variables in Tables 5 and 6 come from CABG, PCI, and length of stay.

In Finland, somewhat less than half of the deaths from coronary artery disease have affected people who have not been in hospital care because of AMI during previous 365 days (EuroHOPE, 2016). We do not have corresponding data from Norway. The possible difference in out-of-hospital deaths can imply the selection of patients varies between countries. However, the greater distance to PCI hospitals in Norway is compensated by the developed helicopter-based emergency services. As already mentioned, a current study could not explain the mortality differences by the organizational variables (Moger et al., 2018). As such, a more comprehensive cost analysis should consider the travel costs related to treatments.

The literature on ageing and health care costs (see, e.g., Karlsson et al., (2018) for a review) typically finds that time to death contributes to smaller health care costs while an increasing age is clearly associated with increasing LTC expenditures (Häkkinen et al., 2008). However, we find that time to death is associated with higher treatment costs. A reason for this result may be that we study an acute care episode, while the literature reviewed by Karlsson et al. (2018) has a broader perspective. In the treatment of AMI patients, disease severity both reduces the probability of having costly procedures and increases the probability of dying (see Table 4).

An important perspective is to what extent differences in costs are related to differences in quality of care. However, this paper does not offer a formal analysis of the potential trade-off between costs and quality. For HEP, the empirical results do not suggest a trade-off between costs and quality at country level since Norway has lower mortality without having higher costs. Additionally, from the one-year perspective, mortality is lower in Norway and higher costs are partly associated with lower mortality. Hence, an argument in favor of a trade-off in the longer run could be made.

We have treated death and time to death as exogenous variables, which are debatable assumptions. A positive correlation between costs and time to death may also be due to a positive impact of hospital costs on time to death. In future research, we would like to elaborate on the mechanisms that create a positive correlation between costs and time to death. Particularly, an important research question is whether increased hospital resources are likely to increase life expectancy for AMI patients. 
This paper explores a limited proportion of the treatments in the health sectors of Finland and Norway. The treatment for patients with AMI attracts attention in the health policy debate and high quality data covering entire countries exist. However, we do not know whether our results also are valid for other acute treatments. Hence, to draw more general conclusions about the treatment costs in the health sectors of the two analyzed countries, more diseases should be included.

\section{Acknowledgements}

Data gathering and analyses are funded by the Health Programme of the European Union (grant number 664691 / BRIDGE Health). Unto Häkkinen acknowledges financial support from the Yrjö Jahnsson Foundation and Finnish Society for Health Economics. The authors are grateful to the journal's referees and editor and to discussant Tanja Karvonen and participants at the Nordic Health Economists' Study Group meeting in Helsinki $21-23$ August 2017 for comments and suggestions that we think have improved the paper a lot. The usual disclaimer applies.

\section{References}

Alter, D. A., Franklin, B., Ko, D. T., Austin, P. C., Lee, D. S., Oh, P. I., Stukel, T. A. and Tu, J. V. (2013). Socioeconomic status, functional recovery, and long-term mortality among patients surviving acute myocardial infarction. Plos One, 8(6), e65130.

Alter, D. A., Naylor, C. D., Austin, P. and Tu, J. V. (1999). Effects of socioeconomic status on access to invasive cardiac procedures and on mortality after acute myocardial infarction. The New England Journal of Medicine, 341, 1359-1367.

Busse, R. (2012). Editorial: Do diagnosis-related groups explain variations in hospital costs and length of stay? - Analyses from the EuroDRG project for 10 episodes of care across 10 European countries. Health Economics, 21(Suppl. 2), 1-5.

Cutler, D. M., and Lleras-Muney, A. (2010). Understanding differences in health behaviors by education. Journal of Health Economics, 29, 1-28.

Deb, P., Norton, E. C. and Manning, W. G. (2017). Health econometrics using Stata. College Station TX: Stata Press.

EuroHOPE (2016). Building register-based performance indicators for AMI and ACS using individual-level administrative health care data. Version of August 27.2016 (available http://www.eurohope.info).

Gelbach, J. B. (2016). When do covariates matter? And which ones, and how much? Journal of Labor Economics, 34, 509-543.

Geue, C., Lewsey, C., Lorgelly, P., Govan, L., Hart, H. and Briggs, A. (2012). Spoilt for choice: Implications of using alternative methods of costing hospital episode statistics. Health Economics, 21, 1201-1216.

Hagen, T. P., Häkkinen, U., Iversen, T., Klitkou, S. T. and Moger, T. A. (2015). Socio-economic inequality in procedures and mortality among AMI patients: quantifying the effects along different paths. Health Economics, 24(Suppl. 2), 102-115.

Hetemaa, T. (2014). Socioeconomic differences in the use and outcomes of hospital treatment for ischaemic heart diseases. Tampere: Juvenes Print-Finnish University Print Ltd.

Häkkinen, U., Martikainen, P., Noro, A., Nihtilä, E. and Peltola, M. (2008). Aging, health expenditure, proximity of death and income in Finland. Health Economics, Policy and Law, 3, 165-195. 
Häkkinen, U., Hartikainen, J., Juntunen, M., Malmivaara, A., Peltola, M. and Tierala, I. (2011). Analysing current trends in care of an acute myocardial infarction using PERFECT data. Annals of Medicine, 43 (Supplement), S14-21.

Häkkinen, U., Chiarello, P., Cots, F., Peltola, M. and Rättö, H. on behalf of the EuroDRG group (2012). Patient Classification and Hospital Costs of Care for Myocardial Infarction in nine European Countries. Health Economics, 21(Issue Supplement 2), 19-29.

Häkkinen, U., Iversen, T., Peltola, M., Seppälä, M., Malmivaara, A., Belicza, E., Heijink, R., Fattore, G., Numerato, D., Medin, E. and Rehnberg, C. (2013). Health care performance comparison using a disease-based approach: the EuroHOPE project. Health Policy, 112, 100-109.

Häkkinen, U., Iversen, T., Peltola, M., Rehnberg, C., Seppälä, T. T. and the EuroHope study group. (2015). Towards Explaining International Differences in Health Care Performance: Results of the EuroHOPE Project. Health Economics, 24, 1-4.

Häkkinen, U., Engel-Andreasen, C., Goude, F., Hagen, T. P., Kruse, M., Moger, T., Rehnberg, C. and Peltola, M. (2018). Performance comparison of patient pathways in Nordic capital areas A pilot study. THL — Discussion paper 22/2018. (Available http://urn:fi/URN:ISBN:978-952343-134-8)

Iversen, T., Aas, E., Rosenqvist, G. and Häkkinen, U. (2015). Comparative analysis of treatment costs in EUROHOPE. Health Economics, 24(S2), 5-22.

Karlsson, M., Iversen, T. and Øien, H. (2018). Ageing and health care costs. Oxford Research Encyclopedias, Economics and Finance, Forthcoming.

Kautainen, K., Häkkinen, U. and Lauharanta, J. (2011). Finland: DRGs in a decentralized health care systems. In Busse, R., Geisler, A., Quentin, W. and Wiley, M. (Eds.), Diagnosis related groups in Europe: Moving towards transparency, efficiency and quality in hospitals (321-336). European Observatory on Health Systems and Policies Series.

Lyttkens, C. H., Christiansen, T., Häkkinen, U., Kaarboe, O., Sutton, M. and Welander, A. (2016). The core of the Nordic health care system is not empty. Nordic Journal of Health Economics, 4, 7-27.

Manning, W. (2006). Dealing with skewed data on costs and expenditures. In Jones, A. (Ed.), The Elgar companion to health economics (439-446). Cheltenham: E. Elgar Publishing.

Manning, W. (2012). Dealing with skewed data on costs and expenditures. In Jones, A. (Ed.), The Elgar companion to health economics (473-480). Cheltenham: E. Elgar Publishing.

Mihaylova, M., Briggs, A., O'Hagan, A. and Thompson, S. G. (2011). Review of statistical methods for analysing healthcare resources and costs. Health Economics, 20, 897-916.

Moger, T. A. and Peltola, M. (2014). Risk adjustment of health-care performance measures in a multinational register-based study: a pragmatic approach to a complicated topic. SAGE Open Medicine, 2, 1-11.

Moger, T. A., Häkkinen, U. and Hagen, T. P. (2018). Higher mortality among ACS patients in Finland than in Norway: Do differences in acute services and scale effects in hospital treatment explain the variation? Nordic Journal of Health Economics, Published online December, 2018.

Mullahy, J. (2009). Econometric modeling of health care costs and expenditures. A survey of analytical issues and related policy considerations. Medical Care, 47(Suppl. 1), S104-S108.

(C) 2018 by the author(s). This article is an open access article distributed under the terms and conditions of the Creative Commons Attribution license (http://creativecommons.org/licenses/by/4.0/). 


\section{Appendix}

\section{Capital area comparison}

In this separate analysis of capital areas of Norway and Finland, we will check whether including primary care and LTC impacts on the comparison of treatment costs for AMI patients. For the capital areas of Helsinki and Oslo, we have data from primary care and long-term care (LTC) including the health centers. Additional data for primary care and LTC are collected from local municipal registers. For Oslo, the data sources are KUHR (control and payment of health care reimbursement to GPs and private specialists) and GERICA for care services. In the Helsinki area, data are collected from the national Registers for Social Welfare and Health Care and from registers of Helsinki and Espoo (Häkkinen et al., 2018a and 2018b).

Table A 1 shows that the sample of AMI patients treated in the capital areas is not as comparable as in the entire country sample. Patients in Oslo are much older and the share of STEMI patients is smaller than in the Helsinki area. These differences are also reflected in mean values of other variables: mortality figures are smaller in the Helsinki area compared to Oslo.

Table A1: Descriptive statistics of patient composition and patient outcome (capital comparison 2009-2013)

\begin{tabular}{|c|c|c|c|c|c|}
\hline & \multicolumn{2}{|c|}{ Helsinki area } & \multicolumn{2}{|l|}{ Oslo } \\
\hline & & mean & sd & mean & sd \\
\hline a00_39 & 1 if age $<40$ years, 0 otherwise & 0.01 & & 0.02 & \\
\hline a40_49 & 1 if $40 \leq$ age $\leq 49,0$ otherwise & 0.07 & & 0.06 & \\
\hline a50_54 & 1 if $50 \leq$ age $\leq 54,0$ otherwise & 0.08 & & 0.06 & \\
\hline a55_59 & 1 if $55 \leq$ age $\leq 59,0$ otherwise & 0.10 & & 0.08 & \\
\hline a60_64 & 1 if $60 \leq$ age $\leq 64,0$ otherwise & 0.14 & & 0.09 & \\
\hline a65_69 & 1 if $65 \leq$ age $\leq 69,0$ otherwise & 0.13 & & 0.10 & \\
\hline a70_74 & 1 if $70 \leq$ age $\leq 74,0$ otherwise & 0.13 & & 0.09 & \\
\hline a75_79 & 1 if $75 \leq$ age $\leq 79,0$ otherwise & 0.12 & & 0.10 & \\
\hline a80_84 & 1 if $80 \leq$ age $\leq 84,0$ otherwise & 0.11 & & 0.13 & \\
\hline a85_89 & 1 if $85 \leq$ age $\leq 89,0$ otherwise & 0.07 & & 0.14 & \\
\hline a90 & 1 if $90 \leq$ age, 0 otherwise & 0.03 & & 0.12 & \\
\hline Male & 1 if male, 0 otherwise & 0.66 & & 0.59 & \\
\hline basic_edu & 1 if basic education, 0 otherwise & 0.45 & & 0.33 & \\
\hline med_edu & 1 if medium education, 0 otherwise & 0.25 & & 0.42 & \\
\hline upp_edu & 1 if upper education, 0 otherwise & 0.30 & & 0.23 & \\
\hline STEMI & 1 if STEMI, 0 otherwise & 0.47 & & 0.39 & \\
\hline Dhep & 1 if died during HEP, 0 otherwise & 0.06 & & 0.08 & \\
\hline d365 & 1 if died during 1 year, 0 otherwise & 0.12 & & 0.22 & \\
\hline \multicolumn{6}{|c|}{ Continuous variables } \\
\hline Mincome & income based on mean income of income groups & 30587 & 28956 & 33231 & 26629 \\
\hline Lospy & hospital days previous year & 2.19 & 9.81 & 1.82 & 6.25 \\
\hline surv365 & Days alive during 1 year & 330 & 100 & 306 & 123 \\
\hline Observatio & & 2981 & & 5491 & \\
\hline
\end{tabular}


We have extended the two measures of cost used in main national level analysis. The costs during the first hospital episode which includes in addition to the acute hospital stays also stays in rehabilitation and long-term care institutions (like nursing homes) during the first 90 days after the index day if a patient is transferred to these institutions immediately. The second cost measure describing cost during the one-year follow-up include, in addition to hospital inpatient care also other institutional care as well as use of primary and social care services

In the capital comparison, we estimate the predicted costs of hospital care in the same way as in country level comparison. For other services costs were measured using the Finnish standard costs of specific cost items (Kapiainen et al., 2014), which were deflated to 2014 price level. The description of the services and costing methods are described in the Table A2. Data on some cost items (e.g., prescribed drugs, visits to a nurse in primary care, and private treatments) are not available from Oslo and not included in the study. Their share of the total cost is about $6 \%$ in the Helsinki area.

\section{Table A2: Definition of additional services and their costing in capital area comparison}

\begin{tabular}{|l|l|l|}
\hline $\begin{array}{l}\text { Rehabilitation and non-specialised } \\
\text { short term inpatient care. In Helsinki: } \\
\text { includes short-term care (length of stay } \\
\text { less than 90 days in health centres) } \\
\text { and care in psychiatric departments }\end{array}$ & $\begin{array}{l}\text { Standard cost estimates 2011 (Kapiainen } \\
\text { et al, 2014). }\end{array}$ & $226.2 € /$ day \\
\hline $\begin{array}{l}\text { Long-term stay in municipal } \\
\text { institutions }\end{array}$ & $\begin{array}{l}\text { Standard cost estimates 2011 (Kapiainen } \\
\text { et al., 2014). }\end{array}$ & $202.8 € /$ day \\
\hline $\begin{array}{l}\text { Outpatient visits and day surgery in } \\
\text { hospitals }\end{array}$ & $\begin{array}{l}\text { Based on cost function estimates using } \\
\text { individual level cost data from Helsinki } \\
\text { university hospital. }\end{array}$ & $349.2 € /$ visit \\
\hline $\begin{array}{l}\text { Visits to a specialist. In Helsinki: visits } \\
\text { to private specialists. }\end{array}$ & $\begin{array}{l}\text { Standard cost estimates 2011 (Kapiainen } \\
\text { et al., 2014) }\end{array}$ & $286.6 € /$ visit \\
\hline $\begin{array}{l}\text { Visits to doctors in primary care, } \\
\text { including home visits. In Helsinki: } \\
\text { visits to health centre doctor and } \\
\text { private non- specialist doctor. }\end{array}$ & $\begin{array}{l}\text { Standard cost estimates 2011 (Kapiainen } \\
\text { et al.,2014) }\end{array}$ & $116.8 € /$ visit \\
\hline $\begin{array}{l}\text { Home care. In Norway: assuming } 2 \\
\text { visits per hour }\end{array}$ & $\begin{array}{l}\text { Standard cost estimates 2011 (Kapiainen } \\
\text { et al.,2014) }\end{array}$ & $52.0 € /$ visit \\
\hline
\end{tabular}

The mean cost of the first institutional episode is 1890 Euro higher in the Helsinki area (10350 Euro) than in Oslo (8460 Euro). There are some differences of the structure of the costs: In the Helsinki area, the share of acute hospital care of the total cost of the first institutional episode is $94 \%$ whereas in Oslo, the share is $91 \%$ i.e. in Oslo somewhat more care is given in local hospitals than health centres.

The total one-year costs are slightly (1260 Euro) lower in the Helsinki area compared to Oslo. The differences in patient structure (Table A1) affect the total cost of a longer follow-up. After adjusting for age, gender, STEMI and previous year use of hospital services, the total one-year costs are 1522 Euro lower in Oslo compared to the Helsinki area. There are differences in structure of cost. In the Helsinki area, the share of hospital inpatient care (acute care and rehabilitation) is almost $70 \%$ of total one-year cost where as in Oslo the corresponding figure is $60 \%$. In addition, the share of other visits (including outpatient visits to a hospital and specialist visits) are higher in the Helsinki area (Figure A1). In Oslo, both relatively and absolutely more resources are devoted to home help services, GP visits and long-term institutional care compared with the Helsinki area. 
The regression analysis of costs during first institutional episode shows that now higher income and upper education are both associated with lower cost perspective (Table A3). The magnitude of the estimated coefficient of the country dummy (Finland) is greater than non-adjusted difference.

The analysis of one-year total cost at capital area level gives clearly different results than national level comparison of hospital costs (Table A4). The adjusted costs are about 1100 - 1800 Euro (about 6-9 \%) higher in the Helsinki area than in Oslo. Again, the sign of the estimated coefficients of the included explanatory variables are in most cases the same as for the country comparison, although the absolute magnitudes are somewhat different. The notable exception is that now upper education is associated with 2500 Euros decrease in costs whereas in country level analysis the estimated coefficient of education is not statistically significantly different from zero.

Figure A1: Structure of one-year total cost 2009-2013, Age, gender, STEMI and previous year use of hospital care adjusted

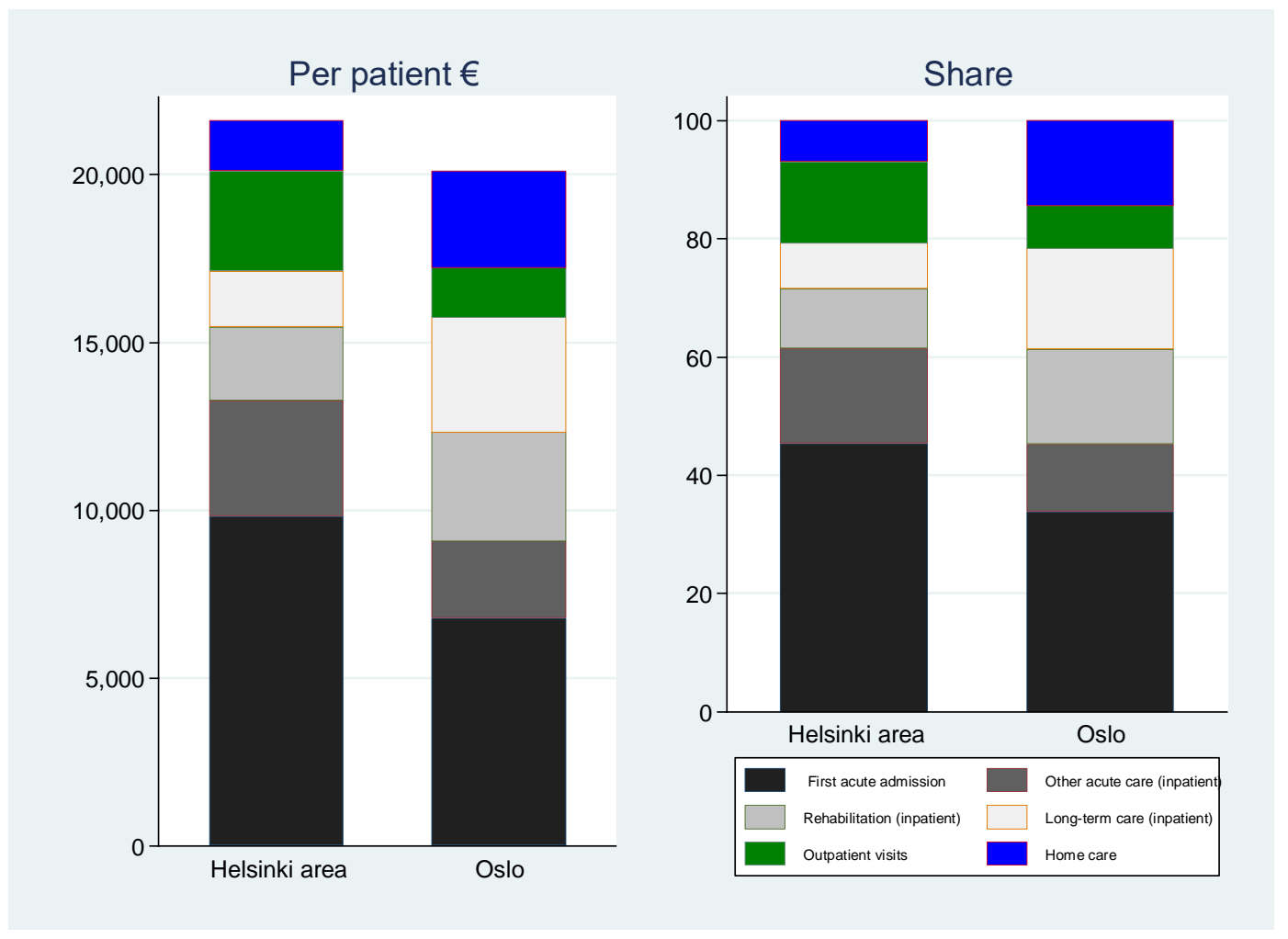


Table A3: First institutional episode cost comparison by OLS - capital areas

\begin{tabular}{|c|c|c|c|c|c|}
\hline & (1) & (2) & (3) & (4) & (5) \\
\hline Helsinki area & $\begin{array}{l}1898.3^{* * *} \\
(208.6)\end{array}$ & $\begin{array}{l}2351.2^{* * *} \\
(186.0)\end{array}$ & $\begin{array}{l}2253.0^{* * * *} \\
(170.4)\end{array}$ & $\begin{array}{l}2345.5^{\text {*** }} \\
(177.4)\end{array}$ & $\begin{array}{l}2227.9^{* * * *} \\
(178.7)\end{array}$ \\
\hline STEMI & & & $\begin{array}{l}875.4^{* * * *} \\
(174.5)\end{array}$ & $\begin{array}{l}1064.7^{* * *} \\
(155.0)\end{array}$ & $\begin{array}{l}1052.4^{* * *} \\
(148.2)\end{array}$ \\
\hline lospy & & & $\begin{array}{l}67.03^{*} \\
(31.54)\end{array}$ & $\begin{array}{l}75.28^{* *} \\
(26.88)\end{array}$ & $\begin{array}{l}73.21^{* * *} \\
(27.89)\end{array}$ \\
\hline dead_hep & & & & $\begin{array}{l}-6380.9^{* * * *} \\
(373.8)\end{array}$ & $\begin{array}{l}-6396.0^{* * * *} \\
(258.9)\end{array}$ \\
\hline mincome $(€ 10000)$ & & & & & $\begin{array}{l}-80.87^{* *} \\
(-25.83)\end{array}$ \\
\hline med_edu & & & & & $\begin{array}{l}-58.15 \\
(201.4)\end{array}$ \\
\hline upp_edu & & & & & $\begin{array}{l}-645.3^{* *} \\
(214.3)\end{array}$ \\
\hline Constant & $\begin{array}{l}8375.4^{* * *} \\
(230.5))\end{array}$ & $\begin{array}{l}8902.0^{* * * *} \\
(334.4)\end{array}$ & $\begin{array}{l}8446.7^{* * *} \\
(370.8)\end{array}$ & $\begin{array}{l}8752.5^{* * *} \\
(372.8)\end{array}$ & $\begin{array}{l}9044.7^{* * * *} \\
(423.0)\end{array}$ \\
\hline $\mathrm{r} 2$ & 0.0132 & 0.0394 & 0.0459 & 0.0865 & 0.0889 \\
\hline $\mathrm{N}$ & 8472 & 8472 & 8472 & 8472 & 8472 \\
\hline
\end{tabular}

Note: The coefficients of age and gender variables not reported.

Table A4: One-year total cost comparison by OLS - the capital areas

\begin{tabular}{|c|c|c|c|c|c|}
\hline & (1) & (2) & (3) & (4) & (5) \\
\hline Helsinki area & $\begin{array}{l}-1121.8^{*} \\
(500.0)\end{array}$ & $\begin{array}{l}1788.9 * * * \\
(450.4)\end{array}$ & $\begin{array}{l}1522.5^{* * * *} \\
(474.9)\end{array}$ & $\begin{array}{l}1462.7 * * \\
(445.5)\end{array}$ & $\begin{array}{l}1372.1 * * \\
(445.5)\end{array}$ \\
\hline STEMI & & & $\begin{array}{l}62.02 \\
(438.6)\end{array}$ & $\begin{array}{l}772.4 \\
(452.2)\end{array}$ & $\begin{array}{l}728.7 \\
(439.4)\end{array}$ \\
\hline lospy & & & $\begin{array}{l}412.7 * * \\
(134,4)\end{array}$ & $\begin{array}{l}432.8^{* * *} \\
(129.5)\end{array}$ & $\begin{array}{l}425.2 * * * \\
(118.9)\end{array}$ \\
\hline d365 & & & & $\begin{array}{l}31440.3 * * * \\
(1956.7)\end{array}$ & $\begin{array}{l}3171.7 * * * \\
(1813.1)\end{array}$ \\
\hline surv365 & & & & $\begin{array}{l}154.4 * * * \\
(5.624)\end{array}$ & $\begin{array}{l}154.1^{* * * *} \\
(5.324)\end{array}$ \\
\hline mincome $(£ 10000)$ & & & & $-340.4 * *$ & $(-71.19)$ \\
\hline med_edu & & & & & $\begin{array}{l}-234.9 \\
(-558.3)\end{array}$ \\
\hline upp_edu & & & & & $\begin{array}{l}-2492.8^{* * *} \\
(608.3)\end{array}$ \\
\hline Constant & $\begin{array}{l}21841.4^{* * * *} \\
(667.1)\end{array}$ & $\begin{array}{l}23784.9^{* * * *} \\
(1081.4)\end{array}$ & $\begin{array}{l}22837.1 * * * \\
(988.9)\end{array}$ & $\begin{array}{l}-32050.9^{* * *} \\
(2321,5)\end{array}$ & $\begin{array}{l}-30715.6^{* * * *} \\
(2131.9)\end{array}$ \\
\hline $\mathrm{r} 2$ & 0.00228 & 0.0976 & 0.115 & 0.226 & 0.230 \\
\hline $\mathrm{N}$ & 8472 & 8472 & 8472 & 8472 & 8472 \\
\hline
\end{tabular}

Note: The coefficients of age and gender variables not reported. 


\section{Appendix references}

Häkkinen, U., Engel-Andreasen, C., Goude, F., Hagen, T.P., Kruse, M., Moger, T., Rehnberg, C., Peltola, M. (2018a). Performance comparison of patient pathways in Nordic capital areas -A pilot study. THL Discussion paper 22/2018.(Available http://urn:fi/URN:ISBN:978-952-343134-8).

Häkkinen, U., Hagen, T. P., and Moger, T. A., (2018b) Performance comparison of hip fracture pathways in two capital cities: Associations with level and change of integration. Nordic Journal of Health Economics, Published online December, 2018.

Kapiainen, S., Väisänen, A., Haula (2014). Terveydenhuollon yksikkökustannukset Suomessa 2014. THL raportti 3/2014.

(C) 2018 by the author(s). This article is an open access article distributed under the terms and conditions of the Creative Commons Attribution license (http://creativecommons.org/licenses/by/4.0/). 